\title{
The Law of Instability and Failure of the Slope of Dumping Site: A Case Study in Inner Mongolia, China
}

\author{
Weidong Pan $\mathbb{D}$, Jianyang Luo $\mathbb{D}$, Weiliang Pan $\mathbb{D}$, and Kunming Zhang $\mathbb{C}$ \\ School of Energy and Mining Engineering, China University of Mining and Technology (Beijing), Beijing 100083, China \\ Correspondence should be addressed to Jianyang Luo; jianyangluo@126.com
}

Received 5 October 2020; Revised 6 March 2021; Accepted 21 April 2021; Published 4 May 2021

Academic Editor: Roberto Nascimbene

Copyright (c) 2021 Weidong Pan et al. This is an open access article distributed under the Creative Commons Attribution License, which permits unrestricted use, distribution, and reproduction in any medium, provided the original work is properly cited.

In order to study the law of instability and failure in the process of loading of the south dumping site of Hesgoola Coal Mine, the FLAC 3D numerical simulation experiment and the bottom friction simulation experiment were carried out for the deformation and failure of the slope of the south dumping site, the law of instability and failure in the process of loading of south dumping site is obtained, and the relevant safety precontrol measures and suggestions are put forward. This is of great significance to ensure the safety production of the south dumping site of Hesgoola Coal Mine.

\section{Introduction}

In 2011, due to the severe impact of rain in the rainy season, the large groundwater in the mining area resulted in a large volume local landslide in the northeast of the south dumping site of Hesgoola Coal Mine during the dumping process. Because of the insufficient base bearing capacity of the foundation near the second mining area, the soil at the bottom of the dumping site is bulged. It is easy to lead to large-scale landslide, which may cause serious damage to the second mining area and nearby buildings. Therefore, it is extremely important to study the law of slope instability and failure to ensure the safety of production. Scholars at home and abroad have done a lot of research on the stability and failure evolution of waste dumping site slope.

To improve the containment capacity of the Hesgoula south dumping site, Pan proposed three capacity expansion and increase plans, used GeoStudio software for comparison, and determined the capacity expansion plan [1]. Huang took the open-pit mining slope of a mine in Jiangxi province as the research object, and the failure mode of the slope is determined as follows: slippage along the fault plane-rock plate, bending-tracing the schistosity plane of phyllite, and eventually the failure occurs along the foot of the slope, or "collapse" failure occurs [2]. Wang made a stability analysis of the waste dumping site before and after the boundary adjustment based on the investigation of the engineering geological and hydrogeological conditions of the basement of Yinwan waste dumping site and the mechanical characteristics of the bearing soil of the basement and put forward suggestions for modifying the waste dumping site parameters in the south and north sides of the waste dumping site and adjusting the boundary of the waste dumping site [3]. According to the problems of emerging a large number of cracks in Yinwan dump and occurring landslide in local region, Yao investigated the cracks distribution rule of dump, analyzed the monitoring data, and used limit equilibrium theory and numerical simulation method to analyze the slope damage mechanism and slope effect in potential landslide area on the basis of data [4]. By similar simulation experiment, Fu studied the occurrence and development regularity of slope instability under different water content in Yinwan dump basement and analyzed the deformation mechanism and failure mode of slope under water immersing basement. The result shows that continuous increase of loess basement water content can directly cause destruction and instability of slope, whose deformation mode is the whole sliding trailing edge attachment to the interface between argillaceous loess and the natural loess [5]. To assess the stability of an iron mine waste 
dump slope and predict its hazard scale, Bao used a 3D slope model, and the results show that the safety factor, calculated by the DEM simulation, of the slope is 2.3 [6]. Guan used FLAC3D to analyze the landslide mechanism of the internal dump site in the soft loess substrate of the open-pit mine. The results show that the strength of the rejects and the soft base layer, the height of the rejects, and the slope angle are the main external causes of the destruction of the internal dump. The landslide of the internal dump is mainly due to the tensile and shear damage of the rejects. Shear failure, followed by plastic deformation of the base, eventually causes the internal dump to slip along the base [7]. In order to study the stability of composite slope of open pit and reveal the mechanism of slope sliding, Luo carried out FLAC3D numerical simulation and revealed the influence rule and failure form of the location on the stability of composite slope through stability analysis [8]. Wu developed a numerical model, which can consider the full coupling among the thermal (temperature variation), hydraulic (pore water pressure), and mechanical (stress and displacement) processes. The developed model is employed to analyze slope stability, and the simulated results are seen to coincide well with the results obtained by traditional limit equilibrium calculation. Furthermore, the capability of the developed THM model for predicting the slope performance is validated through comparisons of three case studies in terms of both laboratory experiments and numerical simulations [9]. Hakan Tanyas conducted extensive geotechnical investigations, including geological characterization, in situ and laboratory geotechnical testing, long-term movement monitoring, back-analyses, and possible remedial measures, because a variety of structural discontinuities crossing the slopes of Alipasa feldspar open-pit mine, in western Turkey, caused different types of slope failures, which led to interruptions in ore production [10]. Hassan evaluated several rock mass classification systems developed for rock slope stability assessment against known rock slope conditions in a region of Saudi Arabia, where slopes located in rugged terrains with complex geometry serve as highway road cuts [11]. To better understand the effect of an elevated dump, Kamel performed typical laboratory tests (triaxial and oedometer tests) on the lateritic material. The waste disposal site has been modeled using both limit equilibrium and finite element methods. Different types of finite element models have been run; they take the variation of Young's modulus with depth into account and simulate the effect of construction over various phases. Modeling results are then compared with in situ measurements [12]. Based on a twoscale tessellation technique in Neper, Wang proposed a 3DEC-GBM modeling approach considering inter- and intragrain contact failures to study brittle rock failure and the modeling results indicate that inter- and intragrain contact strength heterogeneity affects not only the peak strength of rock, but also the microcrack spatial location, and hence, the fracture development path and fracture pattern [13]. Zhao studied the brittle coal failure behavior under various axial strain rates from 10 to 3 to $10-2 \mathrm{~s}-1$ experimentally and numerically, observed the strain rate dependence of coal strength, and proposed an empirical relationship to describe the dynamic strength of the coal under various loading strain rates [14]. Lü studied the basic principle of directional fracturing by theoretical analysis, analyzed the stress model of borehole and fracture, and obtained the fracture initiation conditions, propagation process, and morphology [15].

In addition, the bottom friction simulation experiment is also a good research method in slope engineering. Based on eastern slope constructing dump at an open-pit mine in Xinjiang Uygur Autonomous Region, using the orthogonal method to establish an experiment program, Zhao performed a basal contact friction experiment to simulate slope failure, discussed the effect of weak layer, time and dump on slope, pointed out the improvement for basal contact friction experiment, and proposed a reasonable reinforcement time for stability and the importance of reasonable making model. And the experiment of four typical production model fully reflected the failure process of composite slope [16]. In order to verify mine preliminary design, which is 280 meters of open-pit slope stability, Wang first used the floor friction model experiment, simulation of the excavation process of open-pit mine slope stability, and possible failure modes. The results show that the slope in the excavation of gravity in a relatively stable state, the slope excavation, will be a little damage, and failure mode is mainly the excavation surface direction tensile breaking and sliding failure, and the deformation failure is mainly due to the excavation of crack control [17]. Chen applied the self-designed bottom friction testing machine to carry out the simulation test research on the progressive failure rule of jointed rock slope only considering the self-weight effect and obtained the progressive failure rule of one group of joints and two groups of joints. The test results have guiding significance for determining the failure mode of jointed rock slope [18]. Xiao used the bottom friction test to simulate the deformation and failure of the slope, intuitively showed the evolution process of the deformation and failure of the slope, and analyzed the stress distribution in the deformation process and the redistribution of the stress caused by the deformation, which has a high guiding value for judging the stability of the slope, studying the deformation and failure mechanism of the slope and taking the correct slope treatment measures [19]. Based on the analysis and arrangement of the existing geological and design data of Koka gold mine, Wang analyzed the stability of the slope rock mass through limit equilibrium method, finite element strength reduction method, and indoor bottom friction similar simulation test, optimized the possible slope angle, and proposed the feasibility of slope angle optimization [20]. Yin carried out the bottom friction simulation test under different slope heights, taking gently inclined medium thick phosphate rock at the deep part of the east mining section of Jinning-Six Mine as the engineering background, and the results show that the deformation and failure response features of the slope can be divided into three stages: fracture and loose in a small range, unstable failure in a local range, and instability failure in the whole range of slope rock sliding to the goaf. The main deformation and failure modes of the slope are tension cracking, breakage, and sliding failure [21]. Jin carried out 
the multifactor bottom friction simulation test of the high and steep layered rock slope and obtained the deformation law and failure mechanism of the high and steep layered rock slope under the action of self-weight stress, according to the principle of orthogonal design [22].

In this paper, taking the south dumping site of Hesgoola Coal Mine as a study case, FLAC3D numerical simulation and bottom friction similar simulation experiment are used to study the law of instability and failure of the slope of south dumping site of Hesgoola Coal Mine, and relevant safety precontrol measures and suggestions are put forward.

\section{Geology Condition of the Study Area}

The Hesgoola Open-pit Coal Mine, invested and developed by Inner Mongolia Xilinhe Coal Chemical Industry Co., Ltd, is located in the Uragai Jurisdiction, Xilinguole League, Inner Mongolia, China, and in the ridge of the southern section of the Greater Khingan Range, as shown in Figure 1. It is a mountain basin spreading from north to north. The basin is $45 \mathrm{~km}$ long and $5 \mathrm{~km}$ wide on average. The terrain in the basin is generally high in the north (about $960 \mathrm{~m}$ above sea level) and low in the south (about $910 \mathrm{~m}$ above sea level). Strata exposed around coal-bearing basins are Lower Permian light metamorphic rocks and Upper Jurassic volcanic rocks. The basin contains the Lower Cretaceous coalbearing rock series, Tertiary, and Quaternary. According to drilling data, the south dump site layer is mainly composed of discarded material, base silt, and clay in the second mining area, and the fault is not developed. The scale of the first phase of the open pit is $3.0 \mathrm{Mt} / a$, reaching the capacity in 2008. And the scale of the second phase is $15.0 \mathrm{Mt} / a$, reaching the capacity in 2012. The current mining depth has reached $100 \mathrm{~m}$, and the loading height of the three existing dumping sites has reached about $60 \mathrm{~m}$.

A large number of laboratory tests of physical and mechanical parameters of rock and soil were performed by using a quadruple stepless variable-speed strain-controlled direct shear instrument to carry out indoor direct shear test of soil samples and the TCK-1 triaxial test and measurement controller and TSZ10-1.0 strain-controlled triaxial test of soil samples. Combined with the previous geological exploration report and the results of the investigation, the parameters are comprehensively analyzed [23], and the physical and mechanical properties of rock and soil suitable for this study are shown in Table 1. The waste with high moisture content and low strength at the bottom of the waste dump is the key layer to cause the internal damage of the waste. The clay layer with large thickness and high moisture content is the weak layer of basement, which is the main stratum of shear failure of basement [24].

\section{Numerical Simulation Analysis}

3.1. Numerical Model. In this paper, FLAC3D 5.01 is used to analyze law of instability and failure of the slope in the loading process of the dumping site. The calculation model is established according to the typical PM3 profile, as shown in Figure 2.

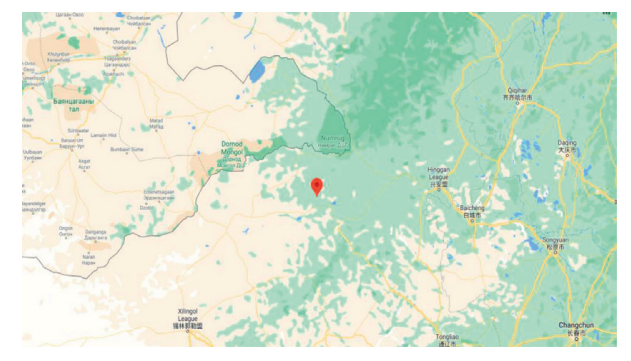

Figure 1: Mine location map.

The model length is $926 \mathrm{~m}$, the model height is $290 \mathrm{~m}$, the slope height is $132 \mathrm{~m}$, and the slope rate is 0.288 . The upper part of the bottom layer of the slope is waste material, the middle part is soft layer (gray blue and gray black clay), and the lower part is bedrock layer. In order to avoid the influence of boundary effect on the calculation results, the range of the dumping site is extended to a certain extent, and the $X, Y$ and $Z$ directions at the bottom of the model are fixed. The Mohr-Coulomb failure criterion is used for strain analysis. According to the indoor test and calculation, the soil parameters used in this model are shown in Table 2.

3.2. Analysis of Numerical Simulation Results. During the loading process of the dumping site, the soil in the unstable area usually undergoes irreversible plastic deformation in varying degrees. Figure 3 is a nephogram of the maximum shear strain rate in the process of loading, showing the magnitude of shear strain in the process, which can essentially describe the progressive failure process of the slope.

When the dumping height is $+975 \mathrm{~m}$ (loading $30 \mathrm{~m}$ ), the maximum shear strain rate is $5.76 \times 10^{-8}$, and small shear strain occurs in the material interior and basement (Figure 3(b)). When the dumping height is $+990 \mathrm{~m}$ (loading $60 \mathrm{~m}$ ), the maximum shear strain rate is $1.74 \times 10^{-7}$, and the range of shear strain is almost unchanged (Figure 3(d)). When the dumping height is $+1020 \mathrm{~m}$ (loading $75 \mathrm{~m}$ ), the maximum shear strain rate is $1.82 \times 10^{-7}$, and the range of shear strain expands, but no obvious shear failure occurs (Figure 3(e)). When the dumping height is $+1035 \mathrm{~m}$ (loading $90 \mathrm{~m}$ ), the maximum shear strain rate is $2.33 \times 10^{-5}$, and from the shear strain nephogram, it can be seen that the shear strain of the basement increases significantly, and the range of shear failure increases (Figure 3(f). Because of the increasing stripping materials, the loading height continues to rise, and the shear strain value of the base clay layer also accelerates to increase. The result is that the clay layer has a tendency of large deformation.

\section{Similar Simulation Analysis}

The bottom friction experiment simulation is physical simulation. The research method of physical simulation applied to the stability analysis of slope rock started in the 1970s. It has two outstanding meanings: one is to be able to directly observe and record the deformation and failure evolution process of the research object, and the other is that the stress distribution state of each stage in the deformation 
TABLE 1: Recommended physical and mechanical indexes of rock and soil.

\begin{tabular}{lccccc}
\hline Lithology & Density $\left(\mathrm{g} / \mathrm{cm}^{3}\right)$ & Moisture content $(\%)$ & Saturation $(\%)$ & Cohesion $(\mathrm{kPa})$ & Inner friction angle $\left(^{\circ}\right)$ \\
\hline Southern discarded materials & 1.85 & 23.5 & 77 & 37.3 & 13.1 \\
Southern silty clay & 1.87 & 27.5 & 85 & 45.9 & 14.9 \\
Southern clay & 1.91 & 30.4 & 92 & 49.5 & 26.3 \\
Western discarded material & 1.92 & 30.8 & 83 & 73.5 & 17.8 \\
Western silty clay & 1.98 & 22.4 & 88 & 46.4 & 23.5 \\
Western clay & 1.87 & 32.2 & 80 & 38.9 & 25.2 \\
Northern discarded material & 183 & 25.8 & 81 & 44.1 & 19.4 \\
Northern silty clay & 1.90 & 24.6 & 87 & 49.7 & 17.7 \\
Northern clay & 1.85 & 32.7 & 84 & 46.0 & 26.5 \\
Eastern discarded material & 1.86 & 27.4 & 91 & 49.9 & 11.2 \\
Eastern silty clay & 1.93 & 31.7 & 87 & 49.6 & 16.5 \\
Eastern clay & 1.84 & 30.6 & & & 22.3 \\
\hline
\end{tabular}

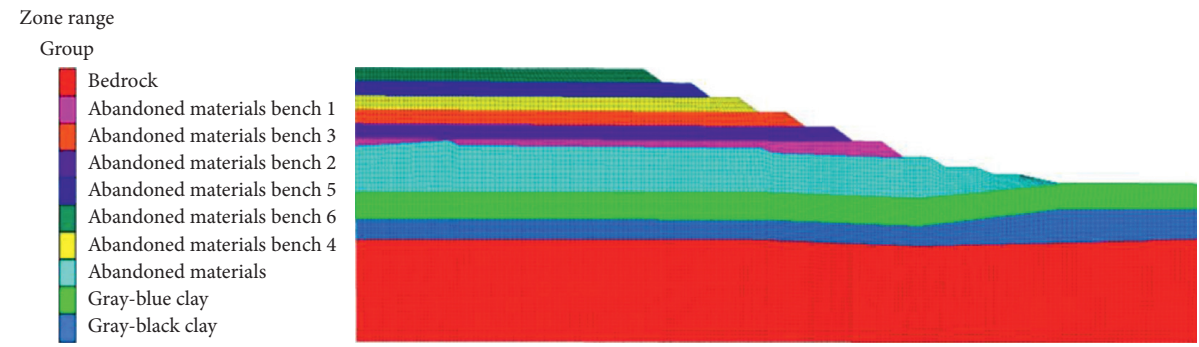

FIGURE 2: Numerical calculation model of the dump.

TABLe 2: Physical and mechanical parameters of rock and soil.

\begin{tabular}{lccccc}
\hline Lithology & Density $\left(\mathrm{g} / \mathrm{cm}^{3}\right)$ & Cohesion $(\mathrm{kPa})$ & Internal friction angle $\left(^{\circ}\right)$ & Modulus of elasticity $(\mathrm{GPa})$ & Poisson's ratio \\
\hline Waste materials & 1.990 & 16.5 & 14.8 & 0.358 & 0.4 \\
Grey blue clay & 1.901 & 20.6 & 20.9 & 0.410 & 0.46 \\
Grey black clay & 2.009 & 25.4 & 26.7 & 0.524 & 0.4 \\
Bedrock & 1.970 & 128.9 & 18.5 & 0.746 & 0.309 \\
\hline
\end{tabular}

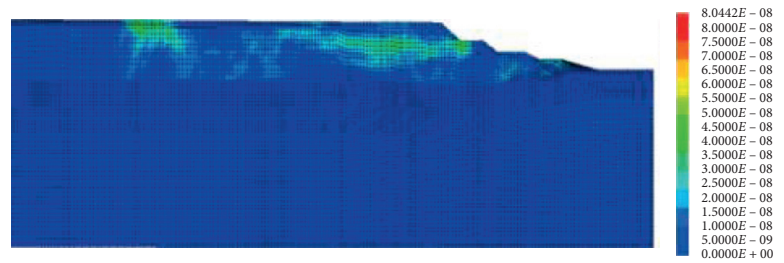

(a)

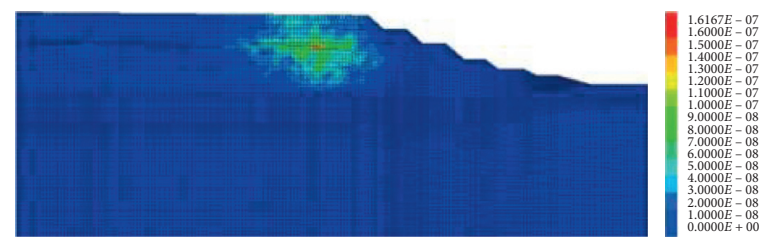

(c)

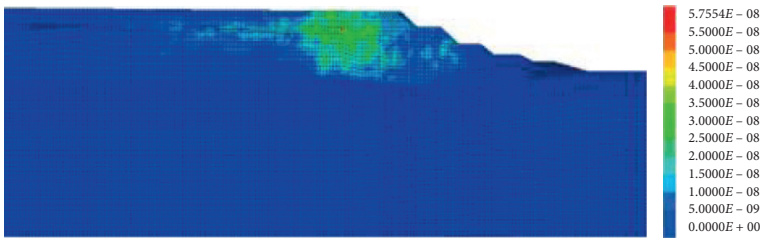

(b)

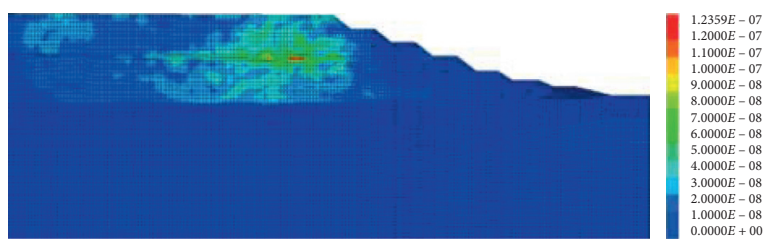

(d)

Figure 3: Continued. 

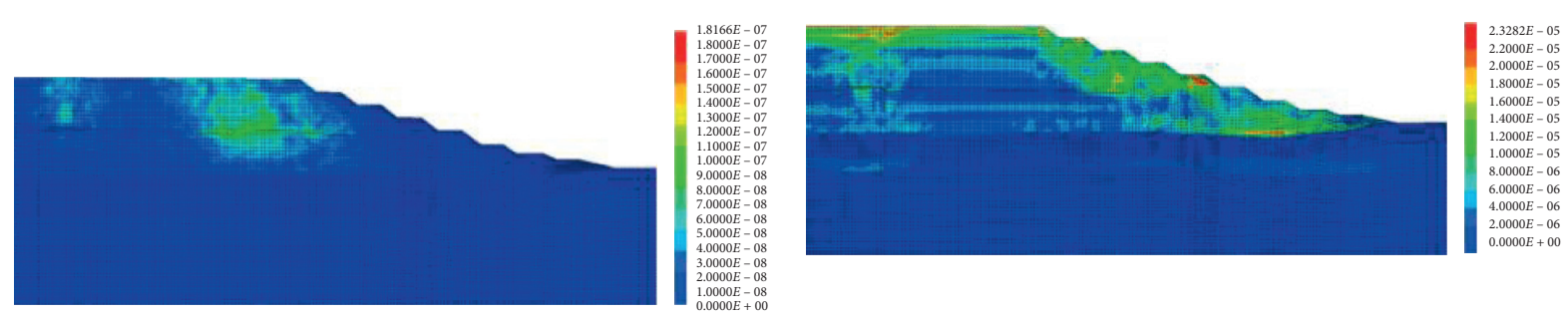

(e)

(f)

FIGURE 3: Cloud strain rate cloud map during different horizontal stacking processes. (a) Dumping height $+960 \mathrm{~m}$ (loading 15 ( $\mathrm{m}$ ). (b) Dumping height $+975 \mathrm{~m}$ (loading $30(\mathrm{~m})$. (c) Dumping height $+990 \mathrm{~m}$ (loading $45(\mathrm{~m})$. (d) Dumping height $+1005 \mathrm{~m}$ (loading $60(\mathrm{~m})$. (e) Dumping height $+1020 \mathrm{~m}$ (loading $75(\mathrm{~m})$. (f) Dumping height $+1035 \mathrm{~m}$ (loading $90 \mathrm{~m}$ ).

and failure process and the redistribution of stress caused by deformation and failure can be obtained through experimental stress analysis [19].

In this paper, a variable-speed bottom friction simulation experimental machine, developed by Wang [25], has been used, as shown in Figure 4. The overall length, width, and height of the machine are $2 \mathrm{~m}, 1.5 \mathrm{~m}$, and $0.8 \mathrm{~m}$, respectively. And the length, width, and height of the testing area are $1 \mathrm{~m}, 1 \mathrm{~m}$, and $0.06 \mathrm{~m}$, respectively. The machine is mainly composed of stepless speed regulating motor, rotating drum, steel platform bottom, seamless tape, and wood model stacking frame.

The motor of the experimental machine is YMT160 stepless speed regulating motor, which can rotate 17.6 circles at the fastest speed and 2.2 circles at the slowest speed every minute. Then, through the secondary deceleration of the belt, the rotating speed of the drum is finally controlled to 1.5-12 circles per minute. In order to adjust the rotation speed of the drum more accurately, a 60-division rotary table is installed on the driving shaft; that is, the data of the rotation speed of the drum is collected every $0.0167 \mathrm{~s}$. In order to reduce the experimental error caused by the deformation of the supporting base or the uneven connection of the belt, the steel plate with high strength and smooth surface is selected as the supporting base, and the seamless belt imported from the United States is selected as the belt. In addition, in order to fully record the whole experiment process and record the destruction process of the dumping site in real time, a high-resolution digital camera is placed directly above the center of the experimental platform to record the whole experiment process.

4.1. Principle of Similar Simulation. The bottom friction simulation experiment is a kind of geomechanical simulation experiment. Compared with other geomechanical simulation experiments, it has the advantages of economy, intuition, simplicity, and easy operation. In recent years, it is widely used in geotechnical engineering and other related research. The bottom friction simulation experiment is an experimental research method based on the similarity theory, which uses the friction between the model and the belt in the experiment to replace the gravity of the model and studies the deformation and failure process of the model under the condition of self-weight. The schematic diagram of bottom friction experiment is shown in Figure 5. The prepared experimental model is tiled in the frame on the bottom plate of the experimental platform, and the top view of the model is similar to the sectional view of the research object. During the experiment, when the driving wheel drives the belt to rotate, the model also moves with it and is blocked by the fixed frame, which causes friction between the model and the belt. Because the friction is generated at the bottom of the model, it is called bottom friction. The base friction $f$ is referred to as

$$
f=\left(F+M_{1} h\right) v,
$$

where $f$ is the stress acting on the model, $N ; M_{1}$ is the bulk density of model material, $\mathrm{N} / \mathrm{m}^{3} ; h$ is the thickness of model, $m ; v$ is the sliding friction coefficient between model and belt.

According to the Saint Venant principle, when the model is extremely thin, it can be considered that the friction generated between the bottom of the model and the belt is evenly distributed on the whole model. At this time, it is equivalent to the fact that the model is only subject to forces parallel to the model direction, while the forces perpendicular to the model direction can be ignored [26-29].

In order to prevent the distortion of the model during the experiment due to the difference between the bottom surface of the model and the surface of the belt, before the bottom friction experiment, the influence of the material strength, the thickness of the model, and other dimensions of the model on the experiment results should be fully considered. Select the most appropriate model size, so that the friction force at the bottom of the experiment can meet the requirements of replacing the model gravity.

4.2. Coefficient of Similarity Condition. In order to ensure that the failure phenomenon of the model in the experiment is similar to the prototype of the dumping site, and to simulate the deformation and failure process of the dumping site more accurately, three similarity relations must be determined in the bottom friction experiment: stress condition similarity, geometric condition similarity, and friction coefficient similarity. Here, the similarity coefficient $K$ is defined as the ratio between the same dimension of the dumping site prototype and the model, and its corresponding expression is as follows: 

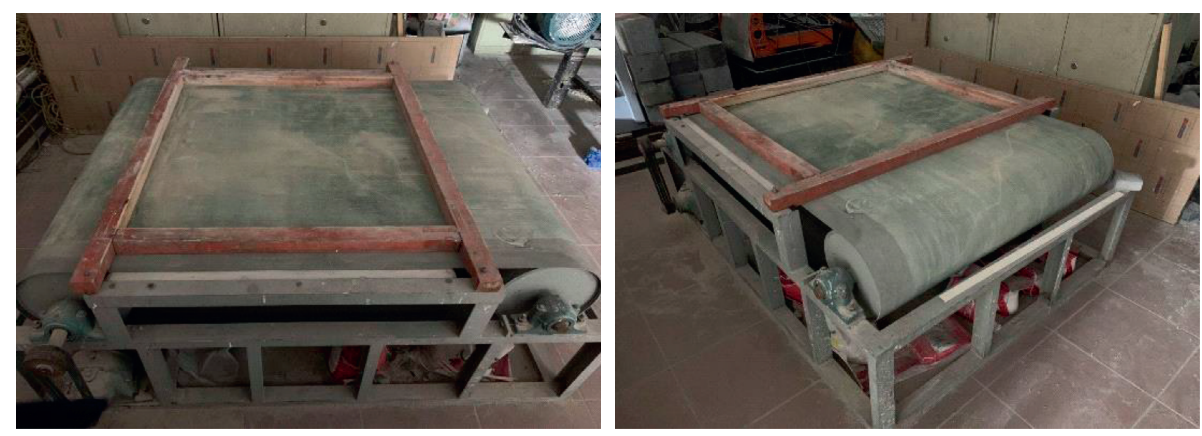

FIgURE 4: Bottom friction simulation experimental machine.

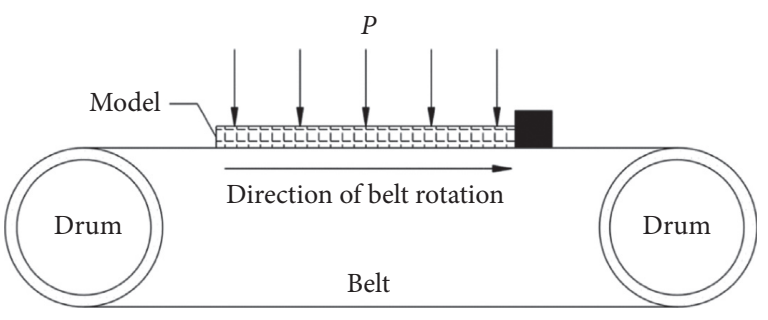

Figure 5: Bottom friction schematic.

(1) Similarity coefficient of stress condition is referred to as equations (2) and (3):

(2)

$$
\begin{aligned}
& K_{R}=\frac{R_{A}}{R_{B}}, \\
& K_{\sigma}=\frac{\sigma_{A}}{\sigma_{B}} .
\end{aligned}
$$

(3) Similarity coefficient of geometric condition is referred to as

$$
K_{H}=\frac{H_{A}}{H_{B}} .
$$

(4) Similarity coefficient of friction coefficient is referred to as

$$
K_{V}=\frac{f_{A}}{f_{B}} .
$$

where $K$ is the similarity coefficient; $H$ is the geometric dimension, $m ; R$ is the material bulk density, $N / \mathrm{m}^{3} ; \sigma$ is the stress, $N ; f$ is the bottom friction coefficient; $\mathrm{A}$ is the dumping site prototype; $\mathrm{B}$ is the simulation model.

According to various conditions of the experiment bench, the above similarity coefficient is determined as $K_{R}=1, K_{\sigma}=500, K_{H}=600$, and $K_{V}=1$. The length, width, and thickness of the model boundary are $0.926 \mathrm{~m}, 0.29 \mathrm{~m}$, and $0.014 \mathrm{~m}$, respectively.

\subsection{Similar Model Parameters and Experimental Methods}

4.3.1. Model and Parameters. During the experiment, in order to make the model easier, it is necessary to simplify the dumping site prototype. The length and width of the simplified drawings are $926 \mathrm{~m}$ and $290 \mathrm{~m}$, respectively. Considering the actual situation of the dumping site, in order to effectively simulate the failure process of the dumping site and effectively compare it with the numerical analysis, the typical PM3 profile of the south dumping site is selected as an example for stability analysis. The simplified PM3 profile is shown in Figure 6.

According to the indoor soil sample physical and mechanical experiment, the material proportioning parameters during the experiment are determined as shown in Table 3.

4.3.2. Experimental Method. According to the size of the model, the amount of materials required for each layer of the model was calculated, and the balance and measuring cup were used to measure the materials. Then, the materials were mixed quickly and evenly, laid in the frame from the bottom to the top, and compacted quickly. After the whole model is laid, the boundary lines between each layer of the dumping site were marked with black ink lines. After the model is dried, the camera was set up to shoot the initial state of the model. Finally, the motor was stared to rotate the belt, and the failure process of the model at the corresponding time point was recorded until the model was completely damaged.

\subsection{Analysis of Simulation Results}

4.4.1. Base Horizontal. The first experiment focuses on the analysis of the process of instability and failure of the dumping site in the process of loading when the basement is almost horizontal. Figure 7 shows the initial state during loading. The specific performance of the dumping site failure process is shown in Figure 8.

As shown in Figure 8, in the process of simulating the gradual loading of waste materials, first arc like crack occurs at the foot of the slope, then to the shoulder of the slope, and finally to the inside of the slope, and the cracks are completely through, and the whole slope slips. When the belt rotates to $0.7 \mathrm{~s}$, the crack similar to circular arc appears at the slope foot (Figure $8(\mathrm{a})$ ). When the belt rotates to $1.3 \mathrm{~s}$, crack appears at the shoulder of the slope (Figure $8(\mathrm{~b})$ ). When the belt rotates to $2.7 \mathrm{~s}$, the crack at the shoulder tends to continue to extend downward. The failure at the foot of slope 


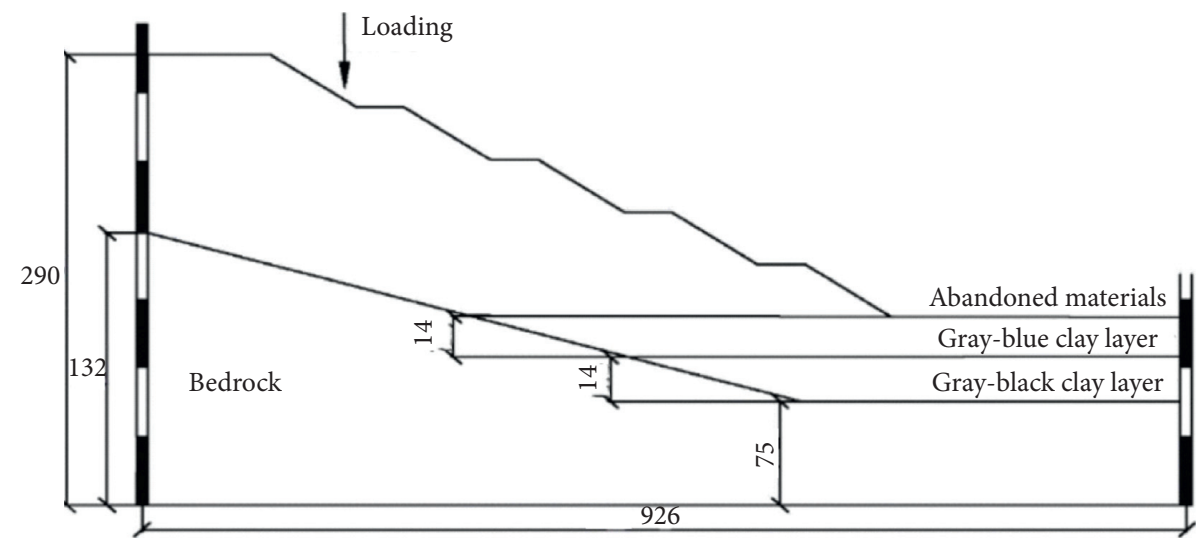

FIgURE 6: Simplified diagram of PM3 model.

TABLe 3: Model material allocation ratio (\%).

\begin{tabular}{|c|c|c|c|c|c|c|c|}
\hline Materiel & Fine sand & Lime & Gypsum & Gravel & Clay & Water & Sawdust \\
\hline Waste materials & 60 & 3 & 1 & 30 & - & 6 & - \\
\hline Grey blue clay & - & - & - & - & 70 & 30 & - \\
\hline Grey black clay & - & - & - & - & 69.8 & 29.7 & 0.5 \\
\hline Bedrock & 80 & 8 & 4 & - & - & 8 & - \\
\hline
\end{tabular}

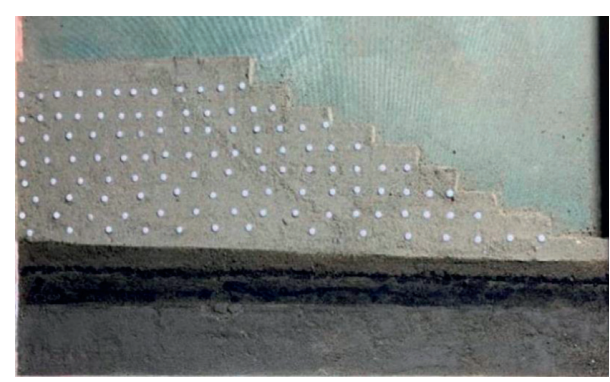

FIGURE 7: Initial model.

is still similar to the arc narrow joint (Figure 8(c)). When the belt rotates to $4.8 \mathrm{~s}$, there are obvious cracks inside the slope, and the range of crack extension is larger, but no crack through (Figure $8(\mathrm{~d})$ ). When the belt is rotated to $6.7 \mathrm{~s}$, the cracks extend down to the middle of the model prominently (Figure $8(\mathrm{e})$ ). When the belt rotates to $8.6 \mathrm{~s}$, the cracks extend obviously in the vertical direction, and the range of crack extension at the slope foot also increases (Figure 8(f)). When the belt rotates to $10.8 \mathrm{~s}$, the range of crack extension increases significantly, multiple crack lines inside the slope have been connected with each other, and the slope foot has been damaged (Figure $8(\mathrm{~g})$ ). When the belt is rotated to $13.9 \mathrm{~s}$, the cracks are completely penetrated, the damage range reaches the maximum, and the whole dumping site is unstable. At the same time, the clay layer in the middle and lower part of the slope is extruded (Figure $8(\mathrm{~h})$ ).

Therefore, through the comparative analysis of the failure state before and after the sliding fracture surface, it can be inferred that the slope first shows settlement at the foot of the slope, resulting in multiple cracks inside the slope, and the extension of the cracks results in the sliding of the soft base clay layer. With the continuous loading, the cracks from the soft base clay layer to the top of the slope are completely penetrated, so the slope slides as a whole.

4.4.2. Base Tilt. The second experiment focuses on the analysis of the process of instability and failure of the dumping site in the process of loading when the basement is in the inclined state. Figure 9 shows the initial state during loading. The specific performance of the dumping site failure process is shown in Figure 10.

As shown in Figure 10, cracks appear at the top and foot of the slope at first and then develop towards the free surface inside the slope, and finally all the internal cracks are connected, causing the overall slope failure and sliding. When the belt is rotated to $1.1 \mathrm{~s}$, the small displacement of the dumping site mainly occurs at the foot of the slope, the crack similar to circular arc appears at the foot of the slope, and the crack appears at the shoulder of the slope (Figure 10(a)). When the belt rotates to $2.9 \mathrm{~s}$, the vertical displacement behind the slope does not change significantly, but the horizontal direction changes significantly (Figure 10(b)). When the belt rotates to $3.8 \mathrm{~s}$, the cracks extend downward. The failure at the foot of slope is still similar to the arc narrow joint (Figure 10(c)). When the belt rotates to $5.6 \mathrm{~s}$, there are obvious cracks in both the vertical and horizontal sides of the slope, and the range of crack extension is larger, but no crack through (Figure 10(d)). When the belt rotates to $7.7 \mathrm{~s}$, the cracks extend down to the middle of the model prominently, and the crack at the foot of the slope also has obvious change trend (Figure 10(e)). When the belt rotates to $9.6 \mathrm{~s}$, the range of crack extension increases, and the cracks tend to connect with each other (Figure 10(f)). When the belt rotates to $11.2 \mathrm{~s}$, the range of crack extension is further expanded, multiple cracks of slope have been connected with each other, and the slope foot and 


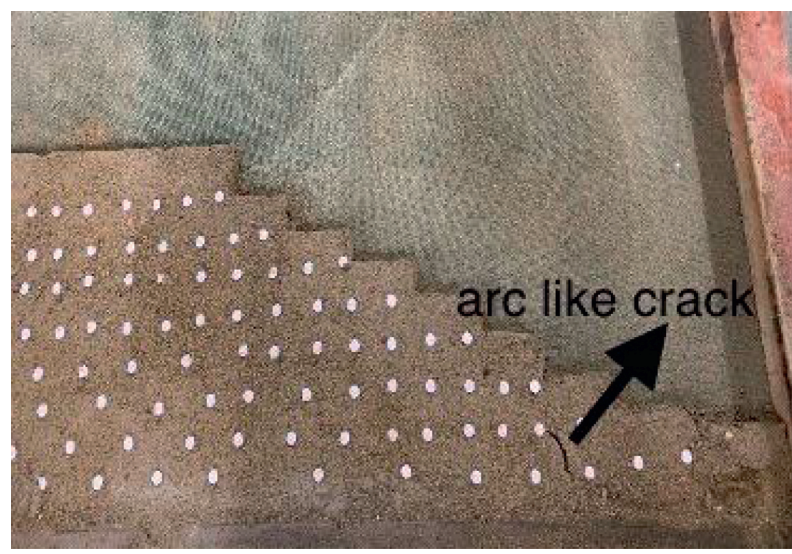

(a)

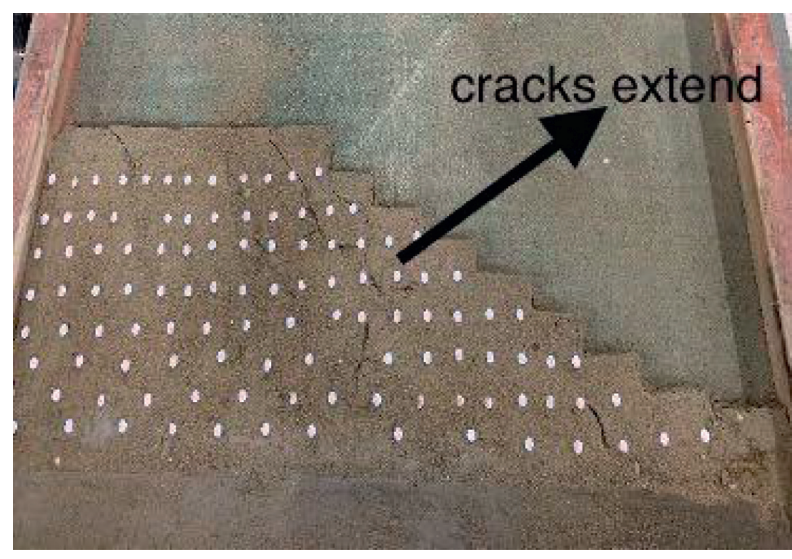

(c)

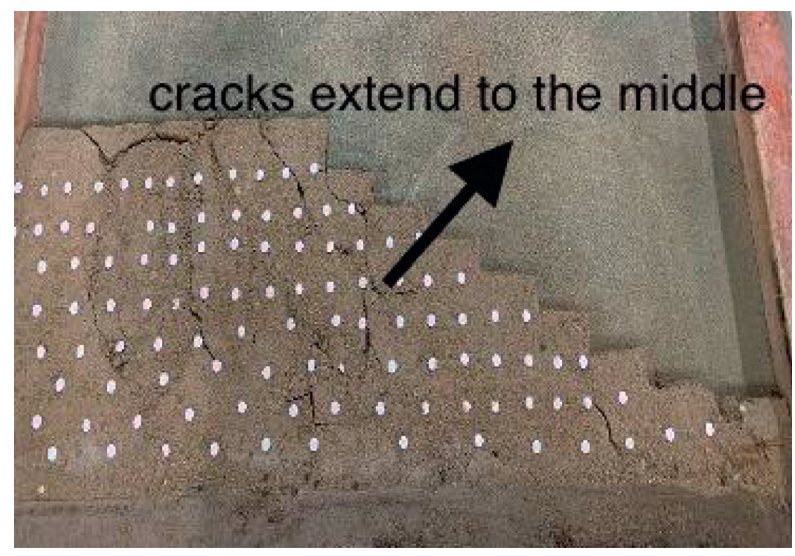

(e)

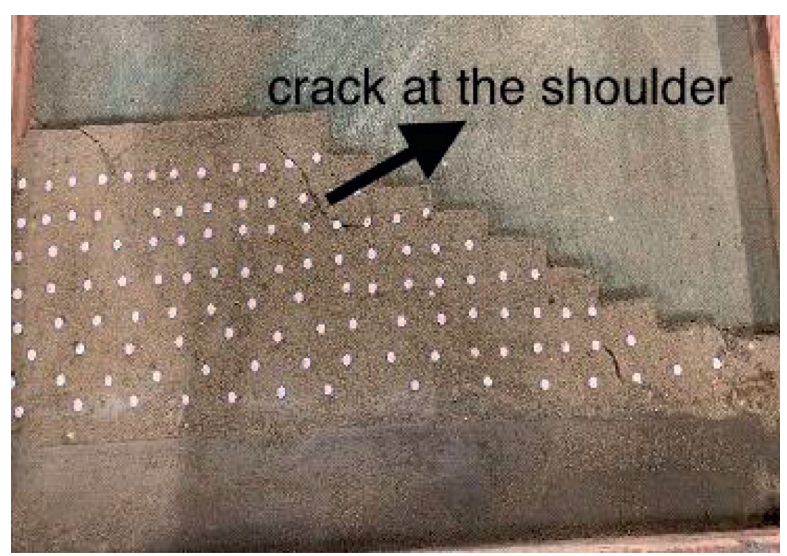

(b)

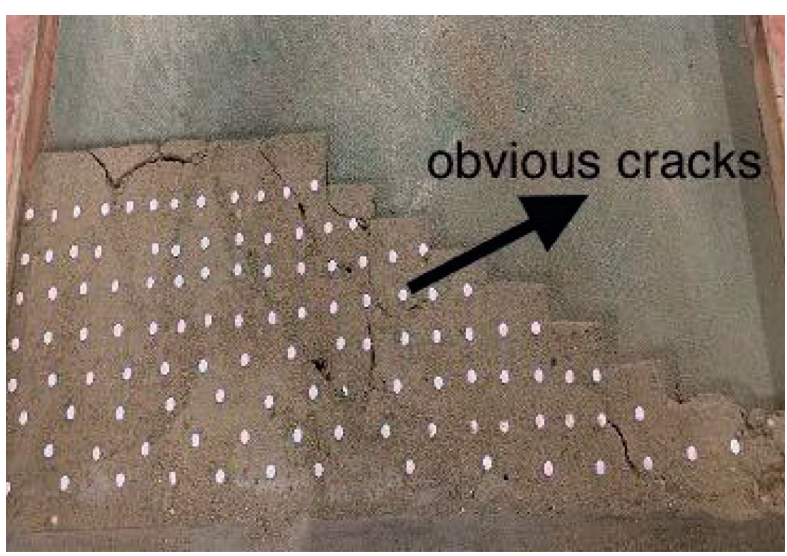

(d)

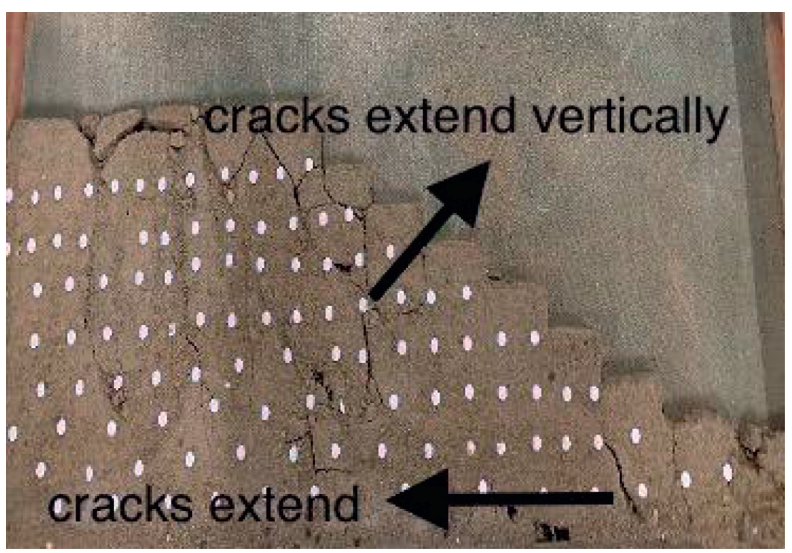

(f)

FIgURE 8: Continued. 


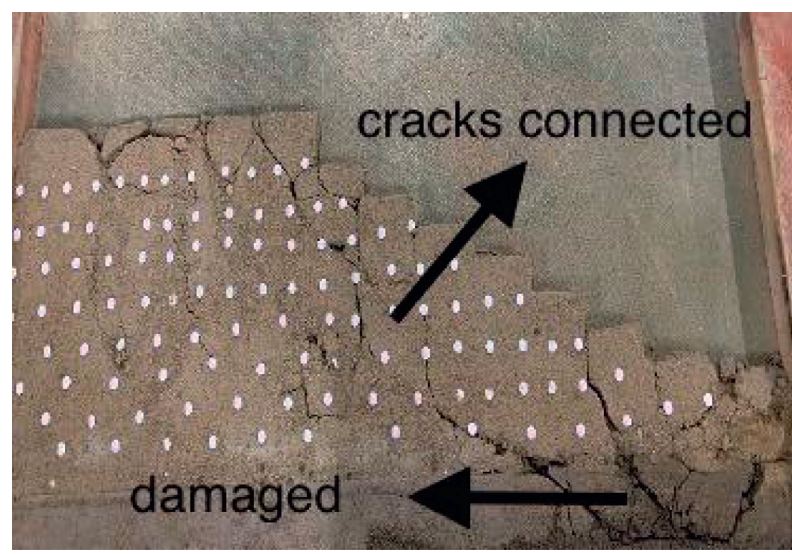

(g)

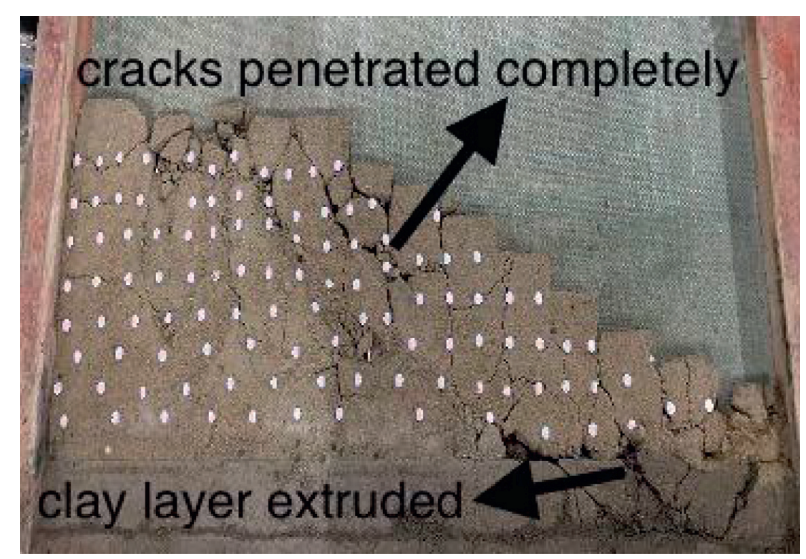

(h)

Figure 8: Destruction process of dumping yard. (a) 0.7 s. (b) 1.3 s. (c) 2.7 s. (d) 4.8 s. (e) 6.7 s. (f) 8.6 s. (g) 10.8 s, (h) 13.9 s.

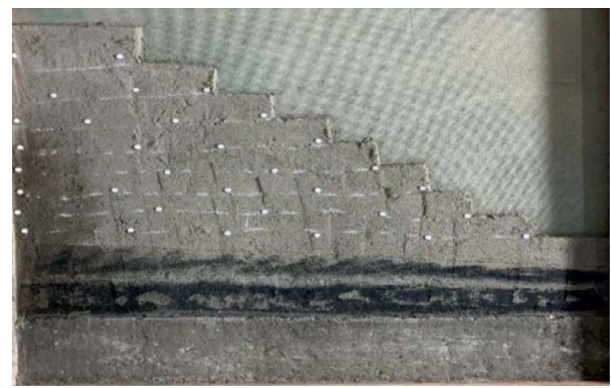

Figure 9: Initial model.

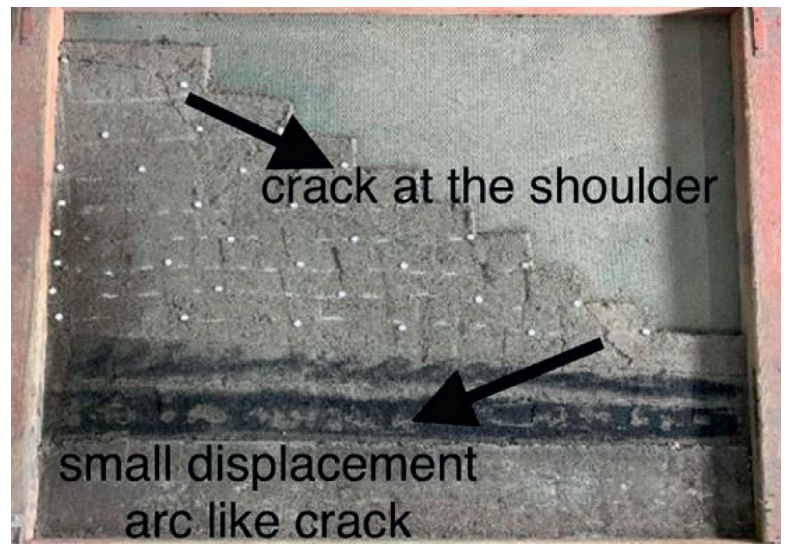

(a)

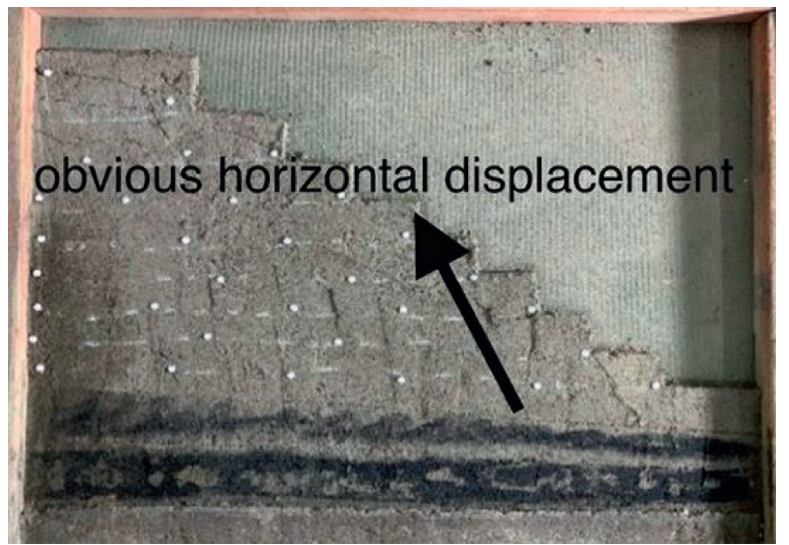

(b)

Figure 10: Continued. 


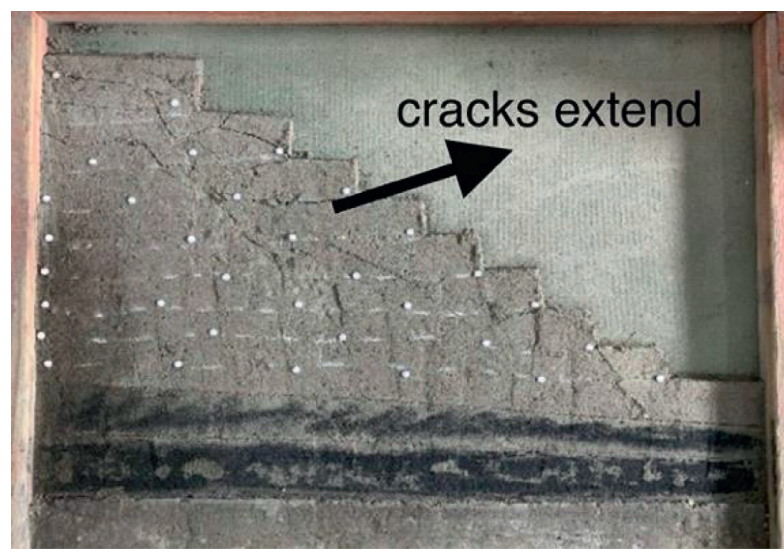

(c)

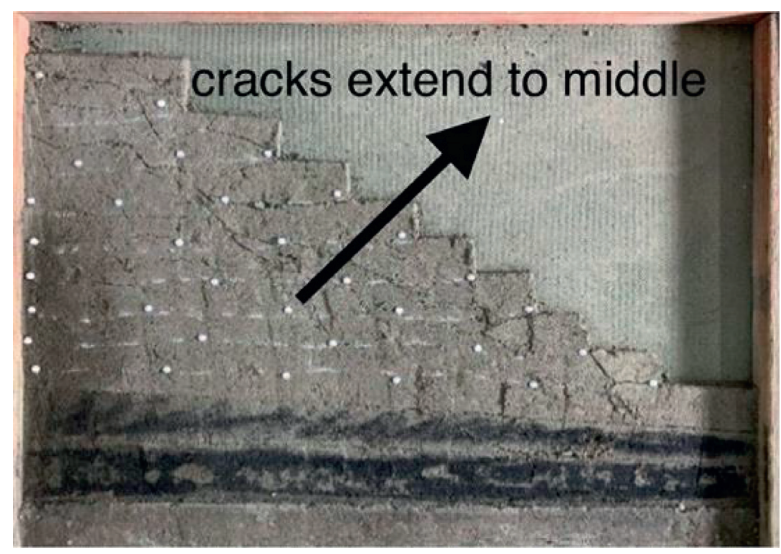

(e)

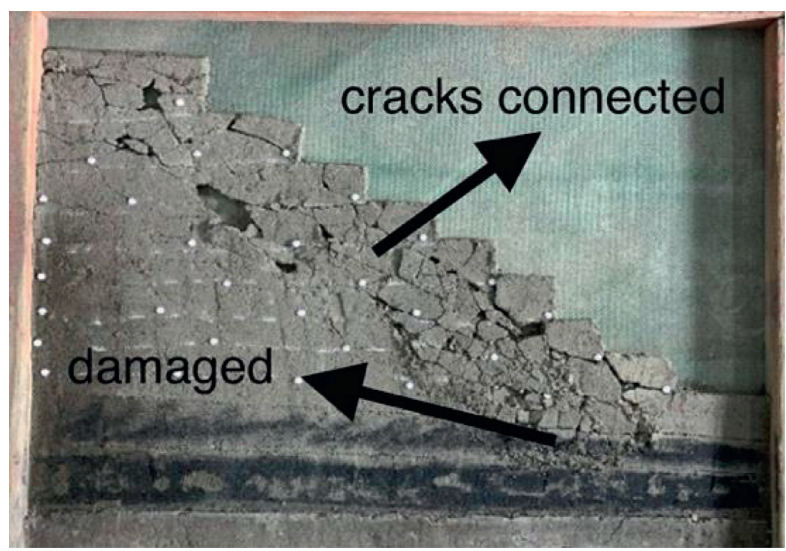

(g)

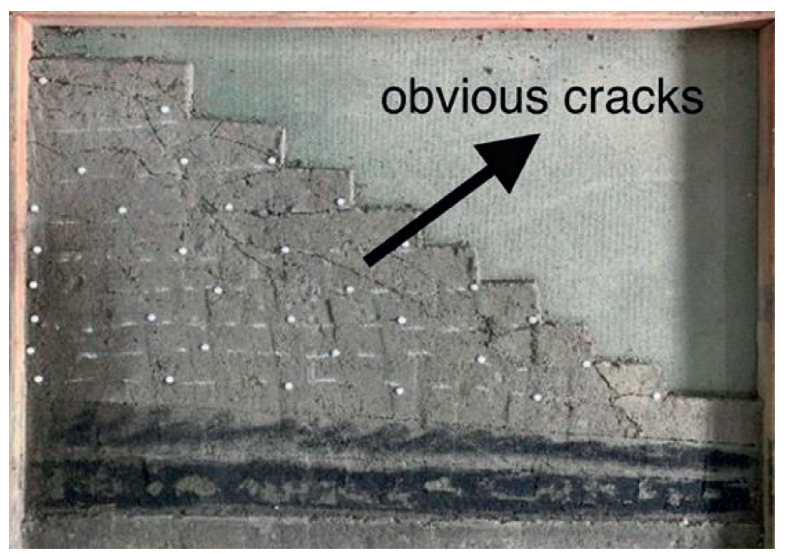

(d)

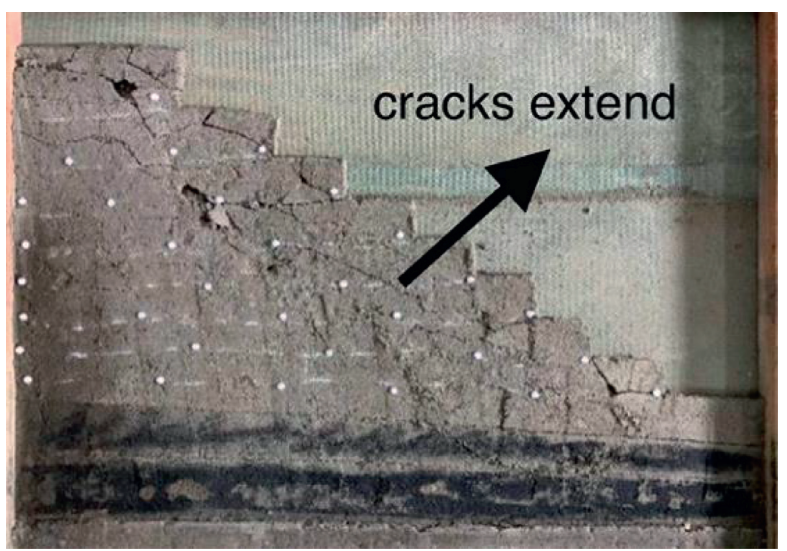

(f)

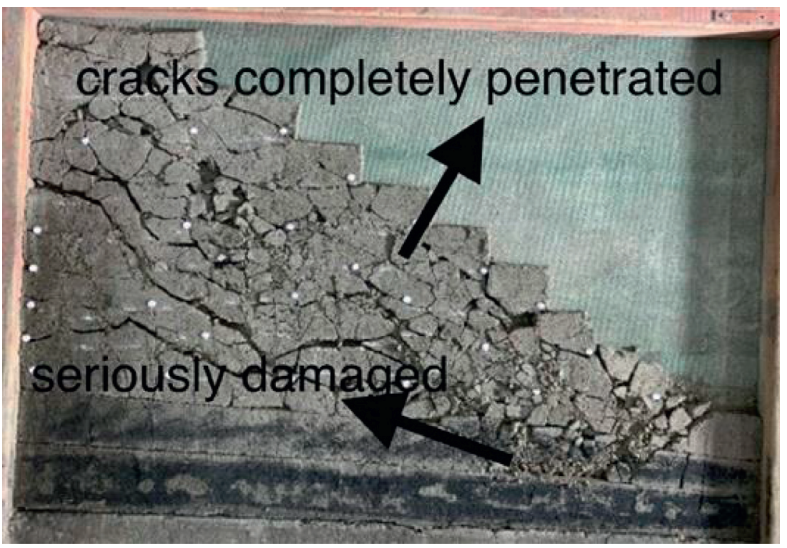

(h)

FIGURE 10: Destruction process of dumping yard. (a) 1.1 s. (b) 2.9 s. (c) 3.8 s. (d) 5.6 s. (e) 7.7 s. (f) $9.6 \mathrm{~s}$. (g) $11.2 \mathrm{~s}$ (h) $13.4 \mathrm{~s}$.

soft basement are also damaged (Figure $10(\mathrm{~g}))$. When the belt rotates to $13.4 \mathrm{~s}$, the cracks are completely penetrated, the damage range reaches the maximum, the soft basement has been seriously damaged, and the whole dumping site is unstable (Figure 10(h)).

The analysis of the experiment results shows that the first failure occurs at the foot of the slope, followed by the middle. At last, many cracks in the slope are connected with each other, which leads to the instability of the whole dumping site. At the same time, the clay layer in the middle and lower part of the slope is destroyed and squeezed out. Because of the increase of the self-weight of the slope, the load of the base layer increases, which leads to instability.

It can be seen that coalescence among fractures would have great influence on the stability of rock masses [30]. The experiment also objectively evaluates and verifies the research of numerical simulation on the instability and failure of the loading of the dumping site. 


\section{Conclusion}

(1) Through the numerical simulation results, it can be seen that, with the increase of dumping height, the shear strain of the basement layer increases significantly, the range of shear failure becomes larger, and the clay layer shows larger deformation. When the dumping height is $+1035 \mathrm{~m}$ (loading $90 \mathrm{~m}$ ), the basement of the dumping site will have shear failure under the action of the overlying load. At the same time, due to the low strength of the clay in the basement of the dumping sit, the waste will have creep deformation with the failure of the basement. Therefore, it can be concluded that the failure mechanism of slope is mainly compression shear failure.

(2) Through the similar simulation experiment results, it can be seen that the first failure occurs at the foot of the slope, followed by the middle. At last, many cracks in the slope are connected with each other, which leads to the instability of the whole dumping site. The experiment also objectively evaluates and verifies the research of numerical simulation on the instability and failure of the loading of the dumping site.

(3) According to the progress of the dumping work in Hesgoola Coal Mine, to avoid the adverse impact on the stability of the dumping site, to ensure the stability of the dumping site during and after the loading process, the safety precontrol measures and suggestions are put forward. During dumping, highstrength dumping shall be avoided to create time for pore water pressure diffusion in the basement and the inside of the dumping materials, so as to avoid the occurrence of landslide disaster. When dumping in the crack area of the flat slope shoulder, a special person shall be assigned to direct the dumping to prevent vehicles from sliding into the slope bottom. Besides, a mobile deformation monitoring and early warning station should be set up in the lower flat plate to monitor the deformation dynamic of the slope during the development of the dumping project in real time, so as to prevent the occurrence of landslide disaster. A mobile slope monitoring station with a distance of about $200 \mathrm{~m}$ should be set up in the potential unstable area of the dumping site to monitor the dynamic deformation of the basement during the waste dumping process and realize the precontrol of landslide risk. What is more, open ditch drainage should be set at the foot of the dumping site to discharge surface runoff formed by atmospheric rainfall.

\section{Data Availability}

The data used to support the findings of this study are available from the corresponding author upon request.

\section{Conflicts of Interest}

The authors declare that they have no conflicts of interest.

\section{Acknowledgments}

The work was supported by the Fundamental Research Funds for the Central Universities (no. 2021YQNY10).

\section{References}

[1] W. Pan, W. Pan, J. Luo, L. Fan, S. Li, and U. Erdenebileg, "Slope stability of increasing height and expanding capacity of south dumping site of Hesgoula coal mine: a case study," International Journal of Coal Science \& Technology, vol. 2020, 2020 prepublish.

[2] R. J. Huang, C. Z. Li, and J. W. Chen, "Study on slippingbending deformation and mechanism of open-pit mining slope," Subgrade Engneering, vol. 04, pp. 211-215+227, 2019.

[3] Z. W. Wang and X. P. Zhu, "Study on the stability of yinwan dump in heidaigou open-pit coal mine," Opencast Mining Technology, vol. 1, pp. 19-20, 2005.

[4] J. H. Yao, "Research on yinwan dump landslide in heidaigou open-pit coal mine," Opencast Mining Technology, vol. 31, no. 181, pp. 10-14, 2016.

[5] X. C. Fu, "Similar simulation of dump slope stability under water immersing basement condition," Opencast Mining Technology, vol. 08, pp. 33-35, 2014.

[6] Y. Bao, X. Han, J. Chen et al., "Numerical assessment of failure potential of a large mine waste dump in Panzhihua City, China," Engineering Geology, vol. 253, pp. 171-183, 2019.

[7] Z. Guan, "Study on stability of in pit dump with soft and weak base floor in open pit mine," Coal Science and Technology, vol. 01, pp. 63-65, 2013.

[8] C. S. Luo, J. S. Shu, and L. Han, "Research on rule of complicated slope sliding in surface mines based on FLAC3D," Industrial Minerals \& Processing, vol. 43, no. 11, pp. 34-36+41, 2014.

[9] D. Wu, T. F. Deng, W. P. Duan, and W. D. Zhang, “A coupled thermal-hydraulic-mechanical application for assessment of slope stability," Soils and Foundations, vol. 59, no. 6, pp. 2220-2237, 2019.

[10] H. Tanyas and R. Ulusay, "Assessment of structurally-controlled slope failure mechanisms and remedial design considerations at a feldspar open pit mine, Western Turkey," Engineering Geology, vol. 155, pp. 54-68, 2013.

[11] B. Hassan and H. Mitri, "Application of rock mass classification systems to rock slope stability assessment: a case study," Journal of Rock Mechanics and Geotechnical Engineering, vol. 9, pp. 993-1009, 2017.

[12] O. Kamel, V. Merrien-Soukatchoff, J. -P. Tisot, and P. JackPierre, "Stability analysis of lateritic waste deposits," Engineering Geology, vol. 68, no. 3, pp. 189-199, 2003.

[13] X. Wang and M. Cai, "Modeling of brittle rock failure considering inter- and intra-grain contact failures," Computers and Geotechnics, vol. 101, 2018.

[14] Y. X. Zhao, S. M. Liu, G. F. Zhao et al., "Failure mechanisms in coal: dependence on strain rate and microstructure," Journal of Geophysical Research: Solid Earth, vol. 119, no. 9, 2014.

[15] H. Y. Lü, F. Liu, L. H. Li et al., "Study on directional hydraulic fracturing of prefabricated fissures in top coal," Journal of Mining Science and Technology, vol. 3, no. 6, pp. 553-560, 2018.

[16] H. Z. Zhao, H. R. Du, H. Y. Su et al., "Basal contact friction experiment of composite slope containing soft rock and multiple seam in open pit," Journal of China Coal Society, vol. 43, no. 10, pp. 2724-2731, 2018. 
[17] Z. D. Wang, Z. A. Wei, X. Y. Wu et al., "High slope floor friction test and numerical simulation analysis," Nonferrous Metals Engineering \& Research, vol. 37, no. 02, pp. 1-5, 2016.

[18] Y. J. Chen, J. C. Wang, L. S. Chang et al., "Experimental research on progressive failure of jointed rock slope," Metal Mine, vol. 08, pp. 14-16+20, 2005.

[19] D. Q. Xiao, H. Hu, and Y. Dong, "Floor-firction simulation for deformation and failure of slope," Technology \& Economy in Areas of Communications, vol. 01, pp. 16-18, 2004.

[20] Z. D. Wang, Stability Study on the Slope of Gold Mine at Eritrea Koka, Chongqing University, Chong Qing, China, 2016.

[21] G. Z. Yin, X. S. Li, and Y. J. Li, "Simulation on the deformation and failure response features and stability of a slope from open pit mining to underground mining under the effecting of excavation goaf by the floor friction model," Journal of University of Science and Technology Beijing, vol. 34, no. 215, pp. 3-10, 2012.

[22] X. P. Jin, "Simulation test on bottom friction of high steep slope in layered rock mass," Metal Mine, vol. 03, pp. 7-9+12, 1998.

[23] J. C. Wang, L. S. Chang, C. H. Xia, W. Shi, and K. Deng, "Study on stability of jointed rock slope of an open iron mine," Chinese Journal of Rock Mechanics and Engineering, vol. 18, pp. 3350-3354, 2005.

[24] W. L. Pan, Study on Stability of Slope and Softening of Soft Base of Dumping Site outside Open pit Mine Soft Base, China University of mining and Technology, Beijing, China, 2019.

[25] Y. J. Chen, J. C. Wang, L. S. Chang et al., "Experimental research on progressive failure of jointed rock slope," Metal Mine, vol. 17, no. 8, pp. 11-13, 2005.

[26] A. R. Khashimov, "An analog of the Saint-Venant principle and the uniqueness of a solution of the first boundary-value problem for a third-order equation of combined type in unbounded domains," Nonlinear Oscillations, vol. 9, no. 1, pp. 115-124, 2006.

[27] Y. V. Babenkova, Y. D. Kaplunov, and Y. A. Ustinov, "Saintvenant's principle in the case of the low-frequency oscillations of a half-strip," Journal of Applied Mathematics and Mechanics, vol. 69, no. 3, pp. 405-416, 2005.

[28] C. D’Apice and S. Chiriță, "On Saint-Venant's principle for a linear poroelastic material in plane strain," Journal of Mathematical Analysis and Applications, vol. 363, no. 2, pp. 454-467, 2009.

[29] A. E. Giannakopoulos, E. Amanatidou, and N. Aravas, "A reciprocity theorem in linear gradient elasticity and the corresponding Saint-Venant principle," International Journal of Solids and Structures, vol. 43, no. 13, pp. 3875-3894, 2005.

[30] W. Pan, X. Wang, Q. Liu, Y. Yuan, and B. Zuo, "Non-parallel double-crack propagation in rock-like materials under uniaxial compression," International Journal of Coal Science \& Technology, vol. 6, no. 3, pp. 372-387, 2019. 